\title{
Chengdu Modern Mansion Research: A Case Study of Liu Xiang Mansion
}

\author{
Xin Cheng \\ School of Civil Engineering and Architecture, Southwest University of Science and Technology, Mianyang, China \\ Email: 527129079@qq.com
}

How to cite this paper: Cheng, X. (2021) Chengdu Modern Mansion Research: A Case Study of Liu Xiang Mansion. Open Access Library Journal, 8: e7771. https://doi.org/10.4236/oalib.1107771

Received: July 19, 2021

Accepted: August 16, 2021

Published: August 19, 2021

Copyright $\odot 2021$ by author(s) and Open Access Library Inc.

This work is licensed under the Creative Commons Attribution International License (CC BY 4.0).

http://creativecommons.org/licenses/by/4.0/

\section{(c) (i) Open Access}

\begin{abstract}
In recent times, a large number of mansions of historical and cultural significance have been built in Chengdu, but some of them have suffered serious damage over time, and some have even been demolished. Taking Liu Xiang mansion as an example, this paper studies the spatial form and construction art of its architecture from multiple perspectives through literature and historical data analysis and field investigation methods, so as to analyze its historical and cultural values and provide a theoretical basis for the conservation and renewal of mansions in Chengdu.
\end{abstract}

\section{Subject Areas}

Architecture

\section{Keywords}

Chengdu, Modern Architecture, Liu Xiang Mansion

\section{Introduction}

Chengdu is a city with 4500 years of civilization of a famous historical and cultural city. It is also one of China's first batch of 24 historical and cultural cities. Under the background of modern Chinese and western cultural fusion ( $\mathrm{Lu}$ liyang, Li Yuanzhang, 2018) [1] in the tide of the development of Chinese urban modernization, appeared a lot of the fusion of Chinese and western culture with rich local culture (Jiang Liangpeng, 2013) [2]. As we all know mansion is one of the typical residential buildings (He yuwei, 2011) [3]. Through field research and the analysis of the number of surveying and mapping data, this paper studies from the perspective of architectural form especially liuxiang masion (Pang Qihang, Chen Ying, 20008) [4], analyzes the foreign architectural culture of tra- 
ditional architecture. The mansion is the continuation of the traditional folk house in Chengdu, on the basis of fusion and absorbed the foreign architectural culture elements (Zhangyang, 2006) [5]. The original lower wood began to turn multi-layer brick structure. The combination of Chinese and Western characteristics appears in the architectural form, and the new orientation of architectural aesthetics and value has emerged. In the development of Chengdu's modern mansions, it has more obvious traditional continuation characteristics. The progress of construction technology and the development of social economy have led to the disappearance of traditional architectural culture, but to a certain extent, its cultural heritage is being passed on. Many survey examples have converted foreign technologies and forms into local experience suitable for local experience, and it is still there today. Has the value of learning reference (Qing Hongling, 2001) [6].

\subsection{Research Purpose}

Chengdu is the earliest developed area in southwest China and one of the 24 historical and cultural cities in the country. In the long-term development process, a relatively unique regional culture has been formed, which has had a long-term and far-reaching impact on its social life, cities and architecture (He Bin, 2015) [7]. Compared with the concession cities and trading cities in the coastal and riverside areas, Chengdu is influenced by foreign cultures (Zhan Liyun, 2013) [8]. The impact was relatively small, modernization started late, and local traditions were preserved. In addition to the collisions and conflicts between western foreign architectural culture and local traditions, urban residential buildings have also begun to modernize through the process of rejection, recognition and integration (Wang Ye, 2008) [9]. Mansion buildings represent the high-level modern residential buildings in Chengdu. It is a modern residence influenced by traditional culture, regional culture and western culture. This residence greatly enriches the functions of traditional low-rise residences. It not only satisfies the daily life of the owner, but also takes care of handling business, entertainment and other requirements. Nowadays, architectural value still exists ( $\mathrm{Wu} \mathrm{Yi,} \mathrm{Nie}$ Kangcai, 2012) [10]. The purpose of the study of Chengdu modern mansions is to analyze the plane, space, facade, decoration and details of Chengdu modern mansion Liuxiang through field inspections of existing residences in Chengdu and the compilation of historical documents.

\subsection{Research Meaning}

The significance of the study of Chengdu modern mansions has historical and practical significance, and the research on mansions architecture. It is helpful to supplement and further improve the history of modern residential buildings in Chengdu. Chengdu has been building a city on a large scale since the 1980s. The rapid development of Chengdu has also caused the disappearance of many traditional streets and modern buildings. Many mansion buildings have gradually 
disappeared. On the one hand, many representative mansion buildings have been demolished. It is of great significance for the data collection and investigation of Chengdu modern mansions. This article takes Chengdu Liuxiang Mansion as an example, from the background and morphological characteristics, it interprets the style and color of Liuxiang Mansion's leveling, standing, section, and architectural construction art. Through research, it can enrich and develop architects to create buildings suitable for Chengdu's regional characteristics. Design ideas. Secondly, provide basic research materials to protect and update Chengdu's modern residential buildings and historic districts.

\section{Research Methods}

First of all, this article sorts out the relevant historical data of Liu Xiang Mansion through case investigation and historical data, collects its drawings and related construction information, and uses it as the basic material to support this thesis. Secondly, collect and sort out historical data closely related to Chengdu's modern residential space. This article uses the methods of sociology and history to study Liu Xiang's mansion. Starting from Chengdu's modern natural and cultural environment; social and economic conditions; building construction system; researching building regulations as well as the various factors that affect the architectural form of the mansion in the design and construction of the building, the regularity and characteristics of space and details. This article mainly uses the following research methods.

\subsection{Literature and Historical Data Analysis and Theoretical Research}

Use the research methods of sociology and history. Through extensive collection of historical data, we can understand the natural environment, social background, technological and economic background of modern Chengdu, as well as the values, customs and life culture of the time. Investigate the background and historical data of typical case owners (educational background, professional experience, life concepts and habits, etc.) through examples.

\subsection{Use the Investigation Method}

Through a combination of comprehensive investigation and key investigation, investigation and research on building examples are carried out. Obtain first-hand information through on-site survey and mapping, photography and personal interviews. It is very convenient to systematically study the residential building form from the aspects of plane layout, space form, entity form and so on.

\section{Factors Influencing the Formation of Modern Mansions in Chengdu}

The formation of modern mansions in Chengdu was influenced by the technological and economic conditions of the human environment, natural environ- 
ment and society. The natural environment includes geographical conditions, local resources, building materials, etc. Humanities, environment, religion, customs, cultural exchanges, social structure, etc. The technical and economic conditions of society include economic conditions, construction technology level, etc. The above factors influence and determine the appearance, development and architectural form of the building. As a high-end residential building, modern houses have also absorbed many advantages of traditional houses. For example, reserve courtyards to organize space and solve ventilation and lighting problems. Advanced foreign methods are applied to the building structure to adapt to the local climate characteristics. For example: the use of brick-wood structure mixed load-bearing system to improve the building's thermal insulation function; in order to prevent moisture, set up a moisture-proof layer, build basements, semibasements, Gao Lejia, etc. For the cold and humid weather in winter, fireplaces are introduced and installed in the living room and bedroom for indoor heating; in order to improve the ventilation and lighting of the room, Western-style floor-to-ceiling windows are introduced to increase the open area of the windows to ensure uniform indoor lighting. The roof is equipped with dormer windows to increase the use function of the attic. These measures not only improve the function of the building, but also more suitable for the needs of modern life.

\section{Liu Xiang Mansion}

\subsection{Background Introduction}

Liu Xiang, who graduated from Lecture Hall, served successively as commander of the 21st Army and chairman of the Sichuan Provincial Government, is a famous anti-Japanese general. The mansion was built in 1933 and is located in Jixiang Street, Anren Town, covering an area of about 1 hectare (Figure 1).

\subsection{Morphological Characteristics}

The mansion seat is east to west. Adopting an independent plan layout, the independent house and the three independent parts of the courtyard together form the main entrance, facing a two-story brick-wood structure. The north-south building faces north-south, with simplified Xieshan roofs and exquisite ridge decoration. Five rooms are wide, with corridors on both sides. The doorway on the central axis is both a stairwell and a passage to the inner courtyard. It shows the garden view of the inner courtyard. At that time, this made the building appear bright and transparent. Western arched windows with strong western architectural characteristics are used on a large area on the front of the building (Figure 2). The gray plastic decoration of the walls and pilasters reflects the influence of the Baroque style. The concise and generous wall colors are mainly gray and white. Liu Xiang used this bungalow as an external reception. It brings together functions such as office, meeting and guest. From the perspective of 


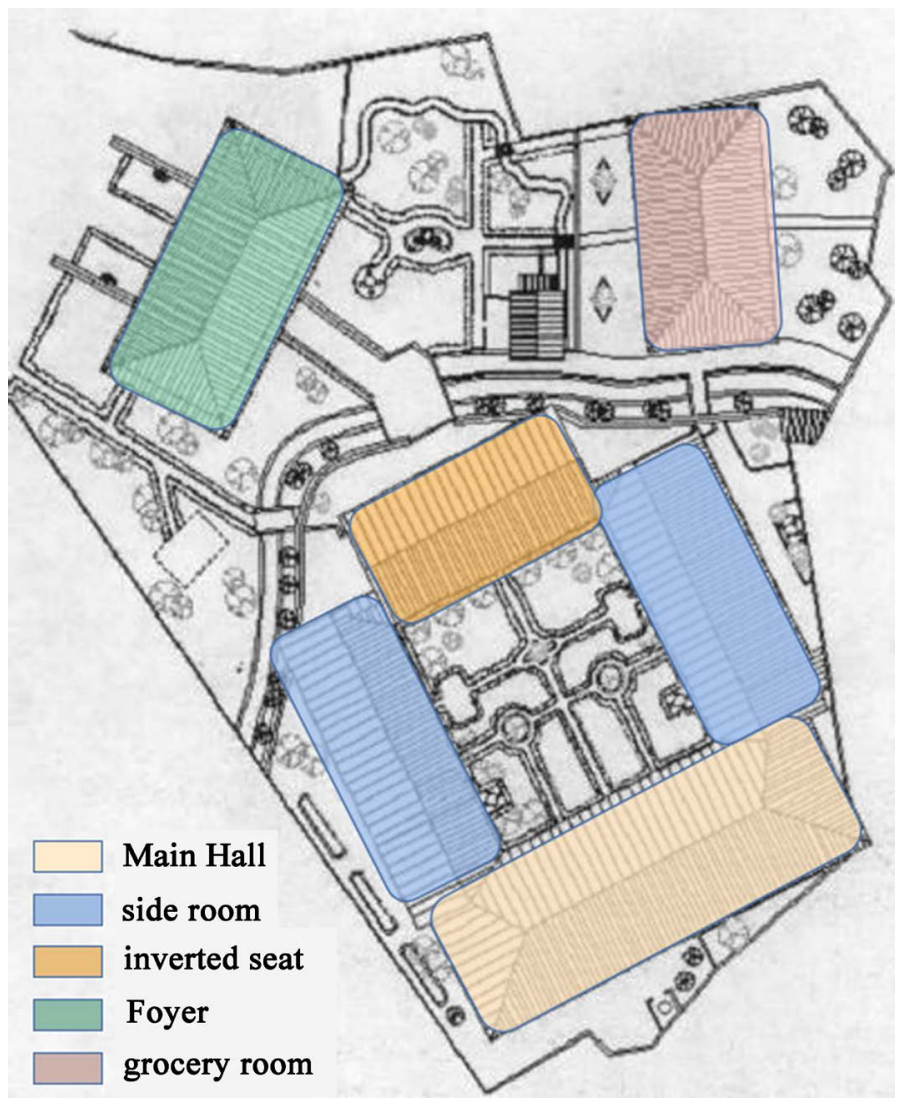

Figure 1. General plan of Liuxiang mansion (photo source: internet).

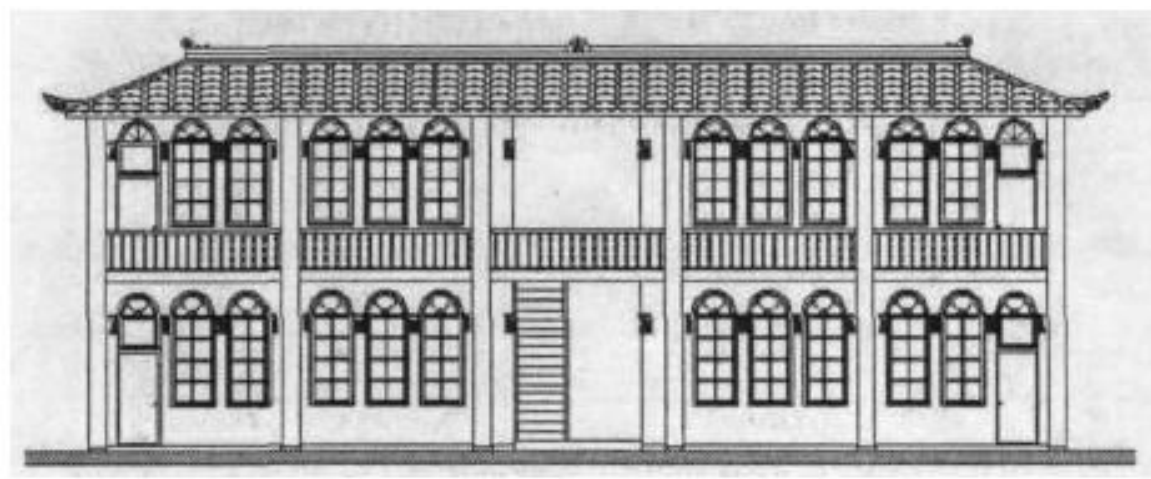

Figure 2. Elevation of Western-style Building (photo source: internet).

"movement and static division" and "internal and external differences", the site selection of western buildings meets the functional requirements. At the rear right of the Western House, there is a small courtyard surrounded by railings and gantry. There is a two-story wooden building with an eave hanging from the roof and a beautiful ridge on the ridge. The lower floor is a brick wall. On one side, the eaves, beams and columns on the first floor form a cantilevered balcony. The overall style is clear New and elegant. Through the Westinghouse, through the garden. There are two roads on the left and right, leading to the courtyard, where the homeowner lives with a separate gate. Turn right to the training 
ground with barracks building. The main function of the barracks on the right is to serve as a barracks and military parade. The main building is from east to west, and it has a large volume. The overall style has both Western Sichuan style and military color. The outer walls of the barracks are simple and generous (Figure 3). The traditional waist eaves as a facade element protrude the horizontal lines, making the building appear stretched out. The shapes of doors and windows are simple and uniform.

The internal function division of the building is very flexible. The ground floor is composed of two large symmetrical spaces, which are convenient for holding events and meetings. The stairs are located under the eaves corridor, separated from the internal traffic flow. The second floor adopts an indoor corridor layout. All rooms are divided on a regular plan, and the doors open to the internal passages. Western-style architectural technology combined with similar functional spaces.

The courtyard house on the left of Liu Xiang's residence is where the homeowner lives. Here, as the material and spiritual center of the family, the traditional layout and facade form are used in accordance with the identity and identity of the manor owner. But the building simplifies the traditional tedious wooden carvings. The entire building has two floors, which makes the living area larger and the image more spectacular (Figure 4). The enclosed courtyard has a large area, and the combination of flowers and plants restores the previous geometric shape.

The Chinese and Western architectural style of the mansion is also reflected in many aspects, such as the construction method of the building, the facade form and the decorative details. In particular, the flat form does not have the traditional shape of multiple courtyards arranged longitudinally along the axis. Need to organize space. The four parts of the West Building, the Miss Building, the Barracks and the courtyard are relatively independent. Relatively independent layout can minimize mutual interference. In the functional area, it is necessary to satisfy life, but also to be able to arrange training and office activities. Meet

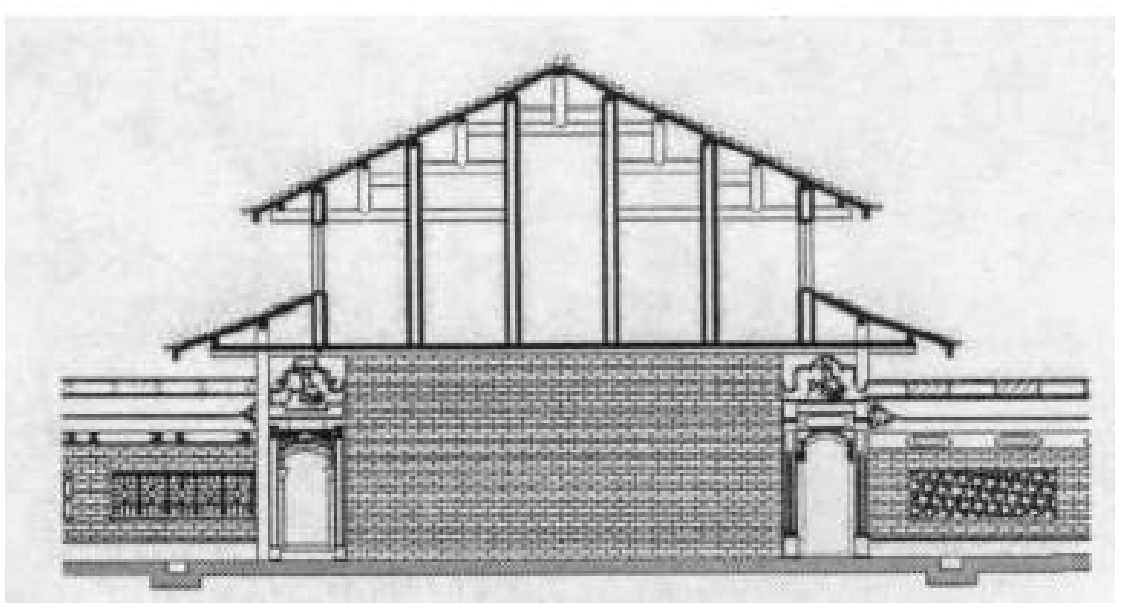

Figure 3. Sectional view of barracks and western-style buildings (photo source: internet). 


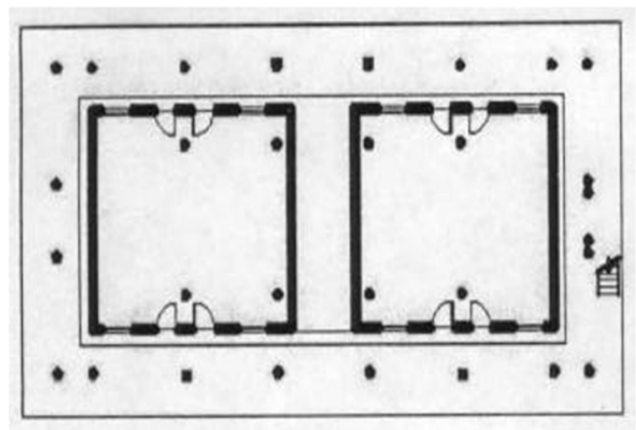

the first floor

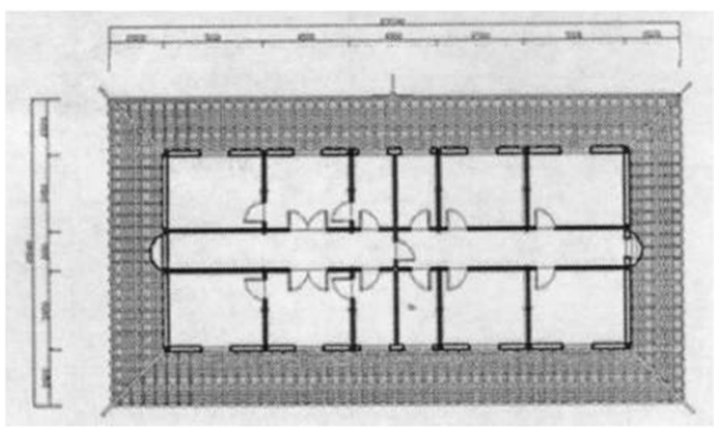

the second floor

Figure 4. The left and right are the first and second floor plans of the barracks and western-style buildings (photo source: internet).

the host for the needs of military life, in Anren Town, a modern traditional residence, this combination of Chinese and Western residences is very unique, and to a certain extent also affects mansions in other places.

It can be seen from the cross-sectional view that the residence of Liu Xiang adopts the common bucket structure of the residential buildings in western Sichuan. The external corridor of the building is actually a corridor formed by waist eaves, which not only meets the environmental conditions and actual functions, but also enriches the volume of the building. This traditional technique is combined with Western-style mountain flowers and cylindrical corridor entrance doors. It embodies the organic and natural combination of Chinese and Western architectural elements. It satisfies the aesthetic needs of the owner of the mansion, not only remembers the ancestors, but also inspires progress and the pursuit of fashion value.

\section{Conclusion}

Natural environmental factors, humanistic environmental factors, social economy and conditions have influenced the formation of modern mansions in Cheng$\mathrm{du}$. This article takes Chengdu Liuxiang Mansion as an example, and interprets the leveling, erection, cross-section and construction art of Liuxiang Mansion from the background and morphological characteristics. In terms of style and color, research can enrich and open up architects to create architectural design ideas suitable for the regional characsteristics of Chengdu. Secondly, it can also provide basic research materials for subsequent related research to protect and update modern residential buildings in Chengdu. Residential buildings and historical districts. The protection and inheritance of the mansion building are inevitable. We must deeply understand the building structure and design methods of the mansion, so as to better use it in the future protection and construction.

\section{Conflicts of Interest}

The author declares no conflicts of interest. 


\section{References}

[1] Lu, L.Y. and Li, Y.Z. (2018) Research on the Architectural Characteristics of Chengdu Modern Mansions. Industrial Construction, 48, 46-51.

[2] Jiang, L.P. (2013) Research on Commercial Protection and Redevelopment Strategies of Modern and Modern Buildings. Tianjin University, Tianjin.

[3] He, Y.W. (2011) Research on the Protection Status of Modern Residential Buildings in Chengdu. Southwest Jiaotong University, Chengdu.

[4] Pang, Q.H. and Chen, Y. (2008) A Preliminary Study of Chengdu Modern Mansion. Sichuan Architecture, 4, 52-53.

[5] Zhang, Y. (2006) On the Regional Cultural Characteristics and Development Ideas of Chengdu Mansion. Journal of China West Normal University (Philosophy and Social Sciences), 3, 72-76.

[6] Qin, H.L. (2001) The Ethical Connotation of Chinese Traditional Architectural Culture. Huaxia Culture, 3, 13-15.

[7] He, B. (2015) Research on the Architectural Design of the Mansion. Kunming University of Science and Technology, Kunming.

[8] Zhan, L.Y. (2013) Talking about the Gate Architecture of Anren Mansion. Sichuan Architecture, 33, 54-55+58.

[9] Wang, Y. (2008) Chengdu Old Neighborhoods-Old Chengdu Mansion and Diaojiaolou. Sichuan Provincial Situation, 8, 41-42.

[10] Wu, Y. and Nie, K.C. (2012) Analysis of the Characteristics of Mansions in Chengdu during the Republic of China. Jiangsu Architecture, 1, 11-14. 